\title{
Continuity from adult-nursing practice to clinical training: Reviewing students' clinical training experience
}

Masako Shomura, Haruka Okabe, Naho Yaguchi, Yoshie Tejima, Satoshi Iwamoto, Daisuke Sakurai, Futoshi Ohyama Faculty of Nursing, School of Medicine, Tokai University, Japan

Received: February 19, 2020

DOI: $10.5430 /$ jnep.v10n6p65
Accepted: March 3, 2020

Online Published: March 17, 2020

URL: https://doi.org/10.5430/jnep.v10n6p65

\begin{abstract}
Objective: In this study, we analyzed a sample of nursing students, focusing on their self-directed learning experiences as they completed a program comprising specialized exercises and examinations and clinical training. Through this, we aimed to identify means of improving nurses' self-directed learning skills during nursing education.

Methods: Sixty-six third-year university students underwent a six-week adult-nursing training involving participatory-type simulated-patient (SP) exercises and objective structured clinical examinations (OSCEs), during which they maintained portfolios in which they noted their experiences and thoughts as they engaged in this education. We analyzed, through qualitative induction, the written data in these portfolios. We followed this by cross-sectionally integrating, using a chronological perspective, experiences reported by the same sample in previous research, consequently clarifying the structure of the students' self-directed learning.

Results: The students' self-directed learning experiences during the adult-nursing training were divided into six classifications. Comparison of self-directed learning in participatory-type SP exercises, OSCE, and training, respectively, showed that few students applied their experience of the SP and OCSE exercises in training. However, during training they showed a strong ability to independently perform reviews of challenges that arose in actual practice and to engage in collaboration. They also showed increased desire to perform nursing.

Conclusions: As the exercises and practice were not conducted consecutively, external experiences may have affected the continuity of the education, and hindered the students' ability to maintain a sense of continuous development. Thus, encouraging students to regularly review their education may enhance their self-directed learning skills.
\end{abstract}

Key Words: Adult nursing, Self-directed learning skill, Simulation exercise, Portfolio, Clinical practice

\section{INTRODUCTION}

As a result of recent, rapid advances in the complexity of nursing treatments, nurses are now required to possess high-level nursing-practice skills. Consequently, methods by which basic nursing education can foster applicable nursing-practice skills ${ }^{[1]}$ (including assessment, planning, care, implementation, and evaluation) have been extensively debated and reported. ${ }^{[2,3]}$ In nursing education, the adult-nursing domain represents a means of acquiring applicable experience in nursing practice, and consequently occupies an important position in nursing curricula. This educational discipline not only teaches students necessary skills through lectures, exercises, and real-world practice, but also accommodates educational interventions designed to improve students' ability

*Correspondence: Masako Shomura; Email: s-masako@tokai-u.jp; Address: 143 Shimokasuya Isehara-shi Kanagawa, Japan. 
to independently and consistently acquire nursing-practice skills. Until 2010, nursing students in our university engaged in participatory-type, simulated-patient (SP) exercises during the first semester of 3rd year; these exercises were designed to foster interpersonal relationship skills. ${ }^{[4]}$ Students also engaged with objective structured clinical examination (OSCE) educational materials. OSCE materials were developed with reference to problem-solving theory, ${ }^{[5]}$ and were designed to help students acquire self-directed practical nursing skill strategies for various settings; after learning such skills, systematic technical evaluations were conducted under set conditions closely matching actual practice. ${ }^{[6]}$ However, during training, which followed the SP and OSCE processes, students have shown inadequate attainment of practical-skillrelated goals $;{ }^{[4,6]}$ this indicated that the students did not sufficiently retain in the training period the sense of selfachievement, ability to address challenges, and ability to independently improve nursing-practice skills that they had developed through the SP participatory-type exercises and OSCE.

In the context of basic nursing education, many previous educational-intervention-based studies have individually focused on lessons, exercises, or training. ${ }^{[7-15]}$ However, few studies have systematically evaluated educational programs from participatory-type SP exercises, through OSCE, to training. Thus, the present research is novel in that it crosssectionally evaluated a single sample of students as they completed an educational program featuring adult-nursing exercises and training. The educational program analyzed is also unique because it attempts, through incorporating OSCE (which has been introduced in Japan's nursing education in $2001,{ }^{[10]}$ to create materials that enhance students' self-directed problem-solving and practical skills. Thus, the experiment of building an educational program that aims to improve nursing-practice skills through developing students' techniques and knowledge of nursing processes may make an extremely important contribution in terms of presenting a method of preparing nurses to meet the expanding needs of society.

This research is significant, in that it considers OSCE (with problem-solving theory) in conjunction with results relating to overseas' strategies ${ }^{[16]}$ and the Japanese medical education process; more specifically, this research describes the creation of an educational program that has high practical applicability for improving nursing-practice skills. By reporting longitudinal results for an intervention involving multiple education subjects and focusing on a single student sample, the findings may have high reliability and validity, and may have implications for future intervention-based research regarding basic nursing training.
In order to identify means of optimizing adult nursing education that comprises participatory-type SP exercises, OSCE, and clinical practice in a continuum, our research objective was to clarify the educational challenges for such continuous education through analyzing students' personal reviews of their experience of SP and OSCE through to clinical training.

\subsection{Definition of terms}

Adult nursing: this discipline teaches medical and surgical nursing knowledge and skills for patients aged 20 years or above. Adult nursing practice is an educational style using simulation to help students acquire competence in medical and surgical nursing at university. In contrast, adult nursing clinical training provides training to students in hospital settings.

Portfolio: A report completed by students at the conclusion of each lesson (including exercises and training). In these reports, students note the material they learned and the challenges they experienced during the lesson. Portfolios help students acquire self-directed learning methods.

Experience: Experience is defined as knowledge obtained through witnessing and performing activities. Thus, in this research "experience" represents students' acquisition of knowledge and skills through seeing and hearing associated actions and events in their surrounding environments.

\subsection{Participatory-type simulated-patient exercises and objective structured clinical examinations}

In the nursing-practice domain, the following two exercises are conducted, based on chronic nursing theory, during the first semester of 3rd year, prior to practice in a specific domain.

Participatory-type SP exercises: These represent paperbased exercises that are designed to foster self-directed and steady development of knowledge of nursing processes, the skills to form interpersonal relations, and the skills to provide nursing support. In the nursing process, SP participation focuses on 1) data-collection and 2) planning of nursing care.

OSCE: With the aim of teaching clinical nursing skills and self-directed learning strategies, and comprising unique OSCE educational materials (videos and actual examples), OSCE exercises are implemented as a systematic technical examination under set, practical conditions (concerning tasks such as measuring blood sugar, injecting insulin, managing continuous drip infusions, administering intravenous injections, and oral administration of medication). 


\subsection{Clinical training}

In the nursing domain, clinical training in nursingdevelopment processes is conducted by allocating one or more adult nurses to acute- and chronic-phase older-adult patients for three weeks at a university hospital. This is performed in the second semester of 3rd year, and the first semester of 4 th year.

\subsection{Research objectives}

1) To clarify, based on students' portfolios, students' experiences of self-directed learning during nursing practice (for both acute- and chronic-phase patients).

2) To contribute to the building of continuous, selfdirected learning experiences by chronologically and crosssectionally integrating the results of research objective 1 with the self-directed learning experiences of the same subject sample as reported in previous research ${ }^{[4,6]}$ regarding the SP and OSCE phases, respectively.

3) To determine the most appropriate mode by which continuous education, from adult-nursing exercises to training, can be presented to encourage students to acquire self-directed nursing-practice skills.

\section{MeTHOdS}

\subsection{Subjects}

The portfolios of approximately 70 3rd-year university nursing students from the 2007 adult-nursing training class (involving chronic and acute phase patients) were analyzed. All participants were recruited from the same university. The university has a variety of departments and the academic resources to develop problem-based learning.

\subsection{Data-collection method}

Prior to this research, participatory-type SP exercises and OSCE educational materials, as well as guidelines for annotating the portfolios, were drafted and prepared, and the SP -OSCE• training sequence was implemented. Before annotating the portfolios, students were given simple instructions to note the main things they had learned and achieved in the lessons, as well as challenges they had experienced and their reflections on the lessons. At the end of each lesson, the portfolios were collected, transcribed, and anonymized (in a manner that allowed us to link all portfolios for each student), and stored.

\subsection{Analytical methods}

Using the written data from all portfolios for analysis, and using the content-analysis recommendations of Belerson ${ }^{[17]}$ as a reference, we performed qualitative induction through the following research approach. Two researchers aggregated sub-categories from the recording units, and then grouped these into categories. Two other researchers calculated the match rates between the sub-categories and the categories they were allocated to. The match rates for this category classification were calculated using Scott's formula, ${ }^{[18]}$ and a rate of $70 \%$ or higher was considered to indicate a reliable match.

Following identification of the students' experiences of selfdirected learning in the adult-nursing training, a comparative study was conducted of the students' learning in the SP, OSCE, and training phases, respectively. Here, the selfdirected learning was described cross-sectionally and chronologically; the results of, and challenges that arise during, such a continuous educational program were clarified; and the most appropriate education method for encouraging students' self-directed acquisition of nursing-practice skills was sought.

\subsection{Ethical considerations}

This research was conducted with the approval of the ethics committees of the institutions with which the researchers were affiliated. Oral and written consent were obtained, and the research was conducted after the evaluation of each lesson was confirmed. The evaluation included a practical test and a routine paper test which took place at the end of the semester. Privacy was protected throughout the research process.

\section{Results}

\subsection{Subject profile}

The portfolios of 66 consenting subjects (61 females [92\%], five males [8\%]) were successfully collected after their completion of adult-nursing training (six weeks; consent rate: $100 \%)$.

\subsection{Structure of the students' self-learning experiences during adult-nursing training}

Forty-seven sub-categories were identified for the participants' self-learning experiences during adult-nursing training; these were collated into 12 categories, and finally grouped into six classifications (see Table 1). Below, subcategories are presented using enclosing square brackets ("[ ]"), categories are presented using enclosing angle brackets ("<>”), and classifications are underlined. Based on Scott's formula, the overall matching rate was $89.7 \%$, indicating high reliability. 
Table 1. Self-directed learning and experience during adult-nursing training

\begin{tabular}{|c|c|c|}
\hline Sub-categories (47) & Categories (12) & Classifications (6) \\
\hline $\begin{array}{l}\text {-A sense of bewilderment and difficulty, as well as distress regarding an } \\
\text { inability to empathize with and manage patients who have communication } \\
\text { difficulties. } \\
\text { - Recognizing the importance of, and difficulties associated with, learning } \\
\text { patients' overall status through verbal and non-verbal communication and } \\
\text { building trust relationships (Three additional sub-categories) }\end{array}$ & $\begin{array}{l}\text { 1. Efforts to overcome the difficulty of } \\
\text { building an understanding of, and a } \\
\text { relationship with, the patient through } \\
\text { communicating with him/her }\end{array}$ & \multirow{3}{*}{$\begin{array}{l}\text { 1. Discovery, through } \\
\text { trial and error, of } \\
\text { means of addressing } \\
\text { challenges regarding } \\
\text { nursing-practice }\end{array}$} \\
\hline $\begin{array}{l}\text {-Nurses should learn the importance of providing appropriate patient care } \\
\text { that accords with families' desires, while continuing to support family-led } \\
\text { problem-solving } \\
\text { (Three additional sub-categories) }\end{array}$ & $\begin{array}{l}\text { 2. Sense of the importance, and difficulties } \\
\text { associated with, supporting both patients and } \\
\text { their families }\end{array}$ & \\
\hline $\begin{array}{l}\text { - Learning the importance of helping patients develop their existing skills. } \\
\text { - Recognition of the importance and challenges associated with providing } \\
\text { care that conforms with patients' individuality and that is based on a deep } \\
\text { understanding of the patients } \\
\text { (Four additional sub-categories) }\end{array}$ & $\begin{array}{l}\text { 3. Sense of the importance of, and difficulties } \\
\text { associated with, providing care that is suited } \\
\text { to patients' unique characteristics and that is } \\
\text { based on a deep understanding of the patients }\end{array}$ & \\
\hline $\begin{array}{l}\text {-Awareness of a lack of technical skill, and recognition of the importance } \\
\text { of acquiring reliable practical skills through diligent practice } \\
\text { - Developing technical proficiency by accumulating practical experience } \\
\text { through OSCE and training } \\
\text { - Recognizing the usefulness of SP-care evaluations, which are not } \\
\text { obtainable during training }\end{array}$ & $\begin{array}{l}\text { 4. Acquisition of skills that complement class } \\
\text { exercises and training experience }\end{array}$ & \multirow{2}{*}{$\begin{array}{l}\text { 2. Enhancing } \\
\text { nursing-practice } \\
\text { skills through } \\
\text { collaborating to } \\
\text { identify challenges }\end{array}$} \\
\hline $\begin{array}{l}\text {-Awareness of a lack of skills and experience regarding the nursing } \\
\text { process, and the challenge of maintaining skills } \\
\text { - Realization of the importance of care that is based on the integration of } \\
\text { information } \\
\text { (Two additional sub-categories) }\end{array}$ & $\begin{array}{l}\text { 5. Feeling, through reviewing training } \\
\text { experience, a sense of improvement in } \\
\text { practical skills, and ability to identify } \\
\text { challenges }\end{array}$ & \\
\hline $\begin{array}{l}\text {-Sense of fulfillment concerning engaging in multiple interpersonal } \\
\text { interactions and improving learning through immersion oneself in } \\
\text { supportive training environments } \\
\text { - Realization of the importance of nurses' responsibilities regarding } \\
\text { accurately performing necessary observations, reports, and consultations } \\
\text { - Realization of the importance of, and difficulties associated with, } \\
\text { interdisciplinary information-sharing and cooperation in health-care teams } \\
\text { (Two additional sub-categories) }\end{array}$ & $\begin{array}{l}\text { 6. Recognition of the difficulties and } \\
\text { responsibilities associated with } \\
\text { information-sharing and cooperation in a } \\
\text { health-care team, while also experiencing a } \\
\text { sense of fulfillment }\end{array}$ & \multirow{2}{*}{$\begin{array}{l}\text { 3. Developing a sense } \\
\text { of responsibility and } \\
\text { solidarity as a } \\
\text { member of a } \\
\text { health-care team }\end{array}$} \\
\hline $\begin{array}{l}\text { - Realization of the importance of nurse-student and inter-student } \\
\text { collaboration for providing patient care } \\
\text { - Sense of responsibility and joy when using practice skills in the ward } \\
\text {-Increased awareness of a nurse's responsibility toward his/her patients } \\
\text { (Two additional sub-categories) }\end{array}$ & $\begin{array}{l}\text { 7. Recognition of the need for personal } \\
\text { responsibility and solidarity in nurse-student } \\
\text { collaboration }\end{array}$ & \\
\hline $\begin{array}{l}\text {-Developing a sense of growth through reviewing training experience and } \\
\text { the challenges encountered } \\
\text {-Acquisition of in-depth learning, not only through active study, but also } \\
\text { through reviewing one's own experiences }\end{array}$ & $\begin{array}{l}\text { 8. Acquisition of in-depth learning through } \\
\text { reviewing personal experiences }\end{array}$ & \multirow{2}{*}{$\begin{array}{l}\text { 4. Improved } \\
\text { understanding of } \\
\text { their lived } \\
\text { experiences during } \\
\text { the adult-nursing } \\
\text { training }\end{array}$} \\
\hline $\begin{array}{l}\text {-Complications arising from recognition of the need to ensure patient } \\
\text { safety and the application of physical restraint } \\
\text {-Improved knowledge of ethical considerations concerning ensuring } \\
\text { patient safety and respecting their decision-making rights } \\
\text { (Two additional sub-categories) }\end{array}$ & $\begin{array}{l}\text { 9. Deepening understanding of patients' } \\
\text { experiences, nursing practice, and ethical } \\
\text { considerations }\end{array}$ & \\
\hline $\begin{array}{l}\text {-Learning the importance of nursing while also identifying one's own } \\
\text { personality } \\
\text { (Two additional sub-categories) }\end{array}$ & $\begin{array}{l}\text { 10. Recognition of the importance of } \\
\text { maintaining one's own nursing perspectives } \\
\text { and individuality when practicing }\end{array}$ & \multirow{2}{*}{$\begin{array}{l}\text { 5. Experiencing } \\
\text { fulfillment and joy } \\
\text { through studying } \\
\text { nursing }\end{array}$} \\
\hline $\begin{array}{l}\text { •Enjoying learning nursing through interactions with patients (One } \\
\text { additional sub-category) }\end{array}$ & 11. Finding enjoyment in nursing & \\
\hline $\begin{array}{l}\text { - Desire to grow as a nurse through acquiring a wide-range of technical } \\
\text { skills and knowledge } \\
\text { (Two additional sub-categories) }\end{array}$ & $\begin{array}{l}\text { 12. Developing a desire to grow as a nurse } \\
\text { through acquiring technical skills and } \\
\text { knowledge }\end{array}$ & $\begin{array}{l}\text { 6. Recognizing } \\
\text { desires and hopes for } \\
\text { the future }\end{array}$ \\
\hline
\end{tabular}


Students' acquisition of self-directed learning skills during adult-nursing training was promoted through a series of cooperative efforts relating to identifying and overcoming challenges. Specifically, these comprised: 1) discovery, through trial and error, of means of addressing challenges regarding nursing-practice, 2) enhancing nursing-practice skills through collaborating to identify challenges, and 3) developing a sense of responsibility and solidarity as a member of a health-care team. Concurrently, students' motivation to engage in self-directed learning was promoted, through
4) improved understanding of their lived experiences during the adult-nursing training, 5) experiencing fulfillment and joy through studying nursing, and 6) recognizing desires and hopes for the future. These classifications were coupled with improved retrospective abilities and an increased desire to perform nursing (see Figure 1). On the other hand, some students encountered difficulties during training because of [a sense of bewilderment and difficulty, as well as distress regarding an inability to empathize with and manage patients who have communication difficulties].

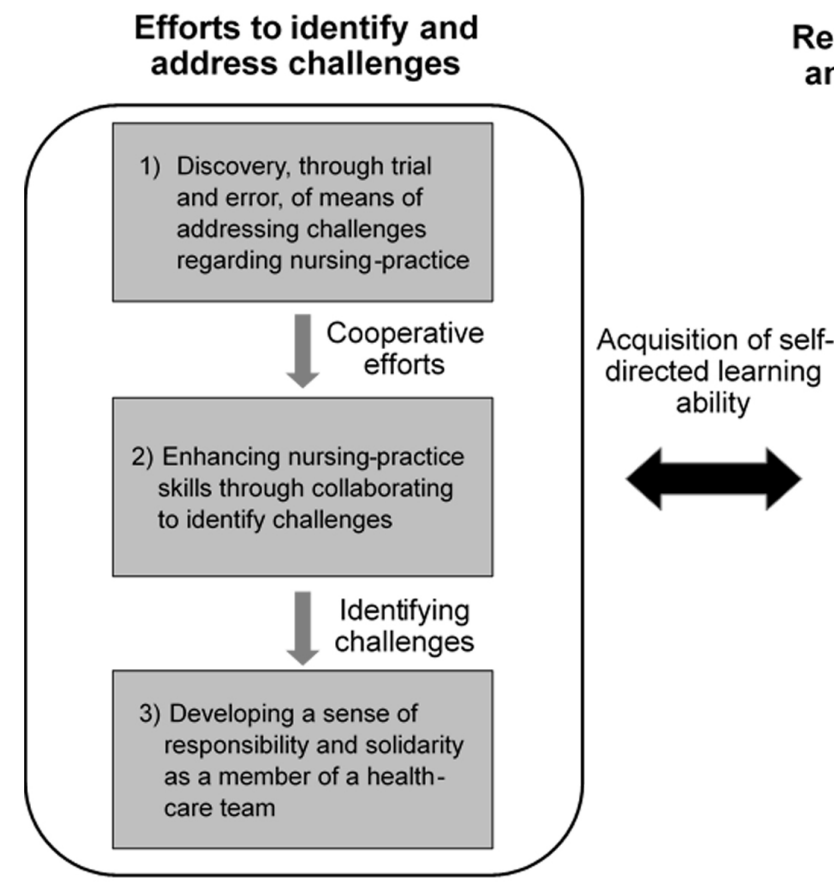

Recognition of the power of retrospection and increased desire to perform nursing

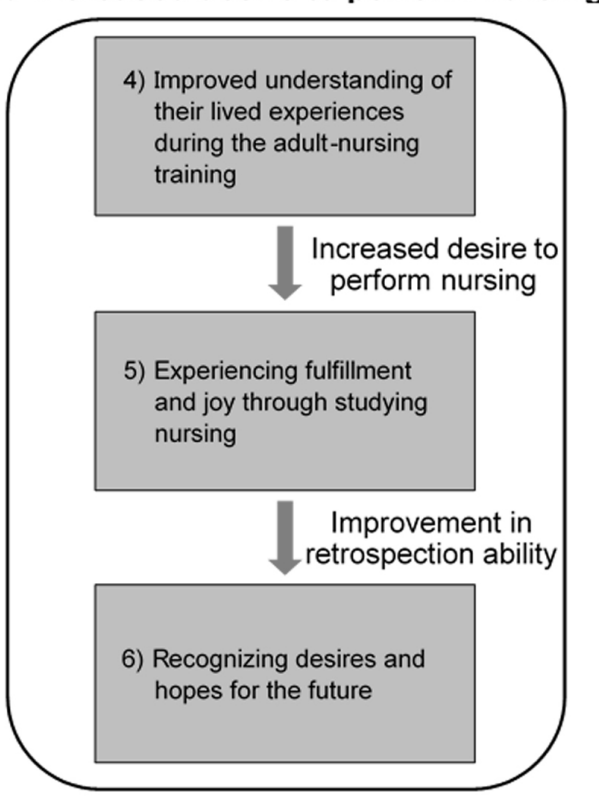

Figure 1. Structure of the students' self-directed learning experiences during adult-nursing training

\subsection{Continuity of self-learning across the exercise and training phases}

The connection between SP and OSCE was clearly noted in two sub-categories regarding experience of self-directed learning in adult-nursing training: [developing technical proficiency by accumulating practical experience through OSCE and training] and [recognizing the usefulness of SP-care evaluations, which are not obtainable during training]. Both of these were integrated into the category <acquisition of skills that complement class exercises and training experience $>$ and, together with another category, $<$ feeling, through reviewing training experience, a sense of improvement in practical skills, and ability to identify challenges $>$, this was integrated into classification 2: enhancing nursing-practice skills through collaborating to identify challenges.

Published by Sciedu Press

\subsection{Structure of continuous self-directed learning, from adult-nursing exercises to training}

Figure 2 shows the learning-structure classifications for a previous study involving $\mathrm{SP}^{[4]}$ a previous study involving OSCE, ${ }^{[6]}$ and the training experience observed in the present study; these are presented in chronological order, from left to right, respectively.

In the left-most box, which concerns SP, learning is displayed as moving from communication and data-gathering difficulties, through acquiring the attitudes and language required to form interpersonal relations, to learning the significance of group work. In SP, learning regarding the nursing process is interpreted both positively and negatively, autonomous learning skills are acquired, difficulties concerning self-learning 
are addressed, and students collaborate to negotiate difficulties. The integration of this phase into the overall learning process allows students, while still experiencing a degree of stress and nervousness, to feel that they acquired practical, engaging knowledge.

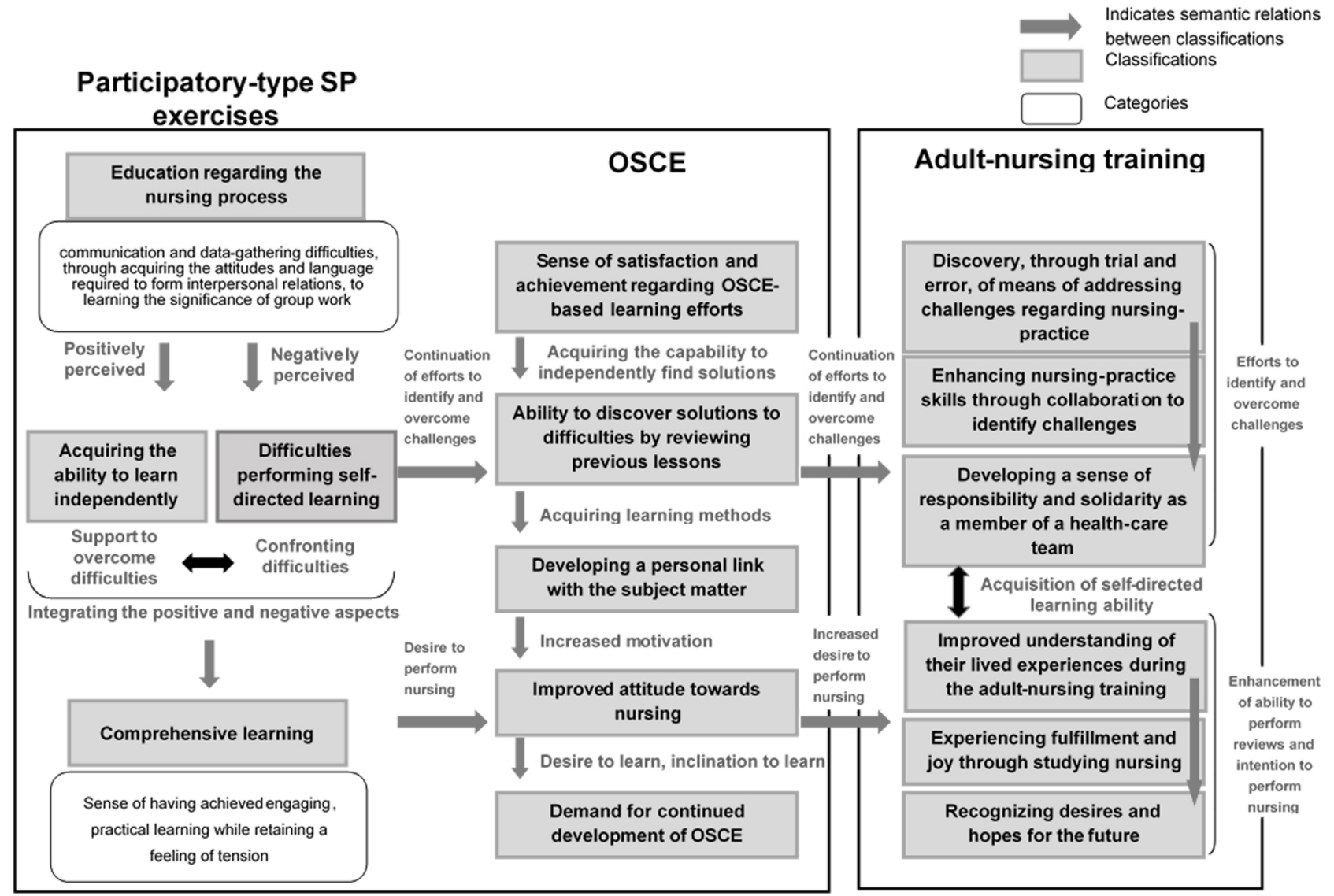

Figure 2. Structure of students' continuous self-directed learning experience, from adult-nursing exercises to training

The center box in the figure concerns OSCE. In this phase, students develop a sense that they are successfully obtaining necessary skills; they achieve this through performing trial and error, reflection, and developing self-efficacy through feedback. In addition, students develop an ability to discover solutions to difficulties by reviewing previous lessons; this contributes to a sense of fulfillment and success regarding their OSCE-related learning. Further, through strengthening their autonomous learning styles, they form personal links with the subject matter, develop a desire and inclination to learn, and desire continuous updating of OSCE material. Transcending the basic learning of techniques, students motivation to learn strengthens as attitudes towards nursing improve.

Concerning continuity from SP, through OSCE, to training, the students repeatedly encountered the challenge of independently overcoming difficulties. Similarly, a heightened inclination to perform nursing was reported during the SP exercises; this strengthened during OSCE, and became even more marked during training. This was because in training, the students' ability to learn from lived experiences improved, which led to an enhanced ability to autonomously review nursing-practice-related challenges. This consequently increased the students' enjoyment and sense of fulfillment regarding studying nursing. Compared to SP and OSCE, when students performed training the number of portfolio entries indicating an improved desire to perform nursing increased notably. An additional characteristic of training was a strong sense of responsibility and solidarity experienced as a result of being a member of a health-care team.

\section{DISCUSSION}

4.1 Characteristics of students' experience of continuous self-directed learning, from adult-nursing exercises to training

A possible reason few nursing students report utilizing skills learned in participatory-type SP exercises and OSCEs in adult-nursing training is that the SP, OSCE, and clinical train- 
ing phases are not scheduled consecutively. The SP and the OSCE are scheduled during spring semester in third grade while clinical training is scheduled during autumn semester in third grade and spring semester in fourth grade. Therefore, there is a time period between three to twelve months. However, the students' memories of their experiences may weaken over time as a result of receiving other lessons and the influences of daily-life factors.

When comparing SP and OSCE learning experiences with those of clinical training, students showed feelings of tension regarding SP and OSCE lessons that closely approximated practice; however, these lessons also resulted in students acquiring a variety of experience that closely resembled training. On the other hand, training differed from the exercises in regard to the presence of teamwork, which enabled students to learn nursing practice through interactions with others.

Increased desire to perform nursing, which arises through developing a sense of enjoyment and fulfillment when studying nursing, was evident in SP and OSCE, but was further strengthened in training.

During the training, students recognized, through developing the ability to reflect on one's own tasks, their acquiring of self-directed practical skills.

\subsection{Developing a program that encourages continuous self-directed learning among students, from adult- nursing exercises to training}

To help students develop practical skills and the ability to perform self-directed learning, it is necessary to create an education program that promotes retrospection throughout the transition from adult-nursing exercises to training.

From the standpoint of promoting continuous, useful, and important learning from exercises to training, and of encouraging students to strengthen their knowledge base, evaluative devices for lesson contents and methods are necessary.

Some students perceived themselves to be at an impasse when they encountered setbacks in training. To prevent students becoming discouraged when they experience setbacks, a follow-up system involving educators, mentors, and interstudent groups may be helpful. Specifically, the use of final interviews regarding training, student conferences, the development of a system that encourages linking training to the content of other domains, and integrated study could be effective for supporting these students.

To reduce the risk of students, over the course of the continuous education, experiencing a decline in their skills as a result of fading recollection and interruptions in the learning process, further use of portfolios could be considered. The use of portfolios not only reinforces learning continuity, Published by Sciedu Press but also allows students to recognize their individual growth and achievement, thereby strengthening their sense of selfaffirmation. Thus, portfolios may also help improve practical skills and self-directed learning ability. Notably, through the development of information and communication technology, e-portfolios are becoming increasingly common; ${ }^{[19]}$ such storable electronic data can facilitate data management, creating a continuous record for not only undergraduate education, but also postgraduate education. ${ }^{[20]}$ Moreover, eportfolios can be accessed regardless of location, which can facilitate reviews of past learning, even during training. ${ }^{[21]}$ Thus, e-portfolios can increase the effectiveness of learning opportunities.

\subsection{Limitations and future challenges}

Constraints regarding facilities and subjects restricted portfolio analysis, meaning the generalizability of these findings is limited. As the numbers of suitable facilities and subjects increase, future research should focus on creating an educational program and conducting intervention studies to verify the interrelations and causes-and-effects identified in the present research results.

\section{Conclunsions}

1) While SP and OSCE enable acquisition of learning topics and the presentation of certain challenges that cannot be presented in training, few students felt that the results they obtained translated into continued personal growth and genuine experience.

2) Through the SP exercises, OSCE, and training, students showed acquisition of self-directed nursing-practice skills, ability to independently address challenges, ability to collaborate with other members of the health-care team, and an increased desire to conduct clinical practice.

3) Some students experienced setbacks in training. As a means of assisting such students, education that promotes, over time, nursing-practice skills and self-directed learning could be created, which could help students when reviewing their training.

\section{ACKNOWLEDGEMENTS}

We would like to express our sincere thanks to all of the students who provided data for this research, and to the various instructors who cooperated in the implementation of the exercises and training. This study was supported by the Japan Society of Private Colleges and Universities of Nursing, Young Scientists Grant, in 2007, and in 2019 by a Special Grant from the School of Health Sciences, Tokai University, for English-language editing fees.

\section{CONFlicts of InTEREST Disclosure}

The authors declare that they have no competing interests. 


\section{REFERENCES}

[1] National Academies of Sciences, Engineering, and Medicine. A framework for educating health professionals to address the social determinants of health. Washington, DC: The National Academies Press; 2016. Available from: http://nationalacademies.org/hmd/Reports/2016/F ramework-for-Educating-HealthProfessionals-to-Add ress-the-Social-Determinants-of-Health.aspx

[2] Nakayama Y, Yokota M. The contents of training of clinical nursing competence between basic nursing education and in-service continuing education. Bulletin of Fukushima School of Nursing. 2012; 14: $1-11$.

[3] Ministry of Education, Culture, Sports, and Technology-Japan. Nursing education model core curriculum: Learning goals for acquiring "Bachelor's-Level Core Nursing Practical Skills" [Internet]; 2017 [cited 2020 Jan 23]. Available from: https://www . mext.go.jp/b_menu/shingi/chousa/koutou/078/gaiyou/ _-_icsFiles/afieldfile/2017/10/31/1397885_1.pdf

[4] Takahashi N, Shomura M, Sato M, et al. The learning of the SP participation type case study practice in adult nursing of chronicity period. Tokai University, School of Health Sciences Bulletin. 2008; 14: 47-54.

[5] Dostál J. Theory of problem solving. Procedia Soc Behav Sci. 2015; 174: 2798-2805. https://doi.org/10.1016/j.sbspro. 2015. 01.970

[6] Shomura M, Sato M, Takahashi N, et al. Learning experience for OSCE enhanced self-motivated adult nursing practice acquirement. Tokai University, School of Health Sciences Bulletin. 2008; 14: 3945 .

[7] Kawashima M, Tomiyama M, Saito R, et al. Studies on the outcomes of simulated-patient-based preclinical training: First report-Changes in students' basic communication skills. Ashikaga University, Nursing Sciences Research Bulletin. 2019; 7(1): 23-34.

[8] Aoki K, Umeda K, Shibusa N, et al. Evaluation of the degree of acquisition of nursing techniques and experience of problems in adult-nursing-science training. Chiba Institute of Science Bulletin. 2018; 11: 119-125.

[9] Suzuki M, Inoue S, Takahashi Y, et al. Educational effect introduced objective structured clinical examination (OSCE) in advanced nursing skills of fourth grade. Journal of the Faculty of Nursing, Iwate Prefectural University. 2018; 20: 39-52.

[10] Yasuko K, Chiemi F. The issues on the introduction of OSCE to nursing education: A report of the visit to the nursing universities that have already introduced OSCE. Kyoritsu Journal of Nursing. 2015; 1: 40-45.
[11] Suzuki K, Hyakuta T, Ogawa S, et al. Degree of inter-evaluator agreement for an OSCE held prior to an adult nursing practicum aimed at college seniors. Japanese Red Cross Hiroshima Coll Nurs. 2015; 15: $69-75$.

[12] Matsumoto Y, Okada J, Hyakuta T, et al. Assessment of a learning program aimed at cultivating practical skills in nursing- An evaluation based on use of the learning environment and OSCE assessment scores. Japanese Red Cross Hiroshima Coll Nurs. 2015; 15: 43-50.

[13] Kaetsu M, Iino Y, Kawai C. Linking preclinical lessons with simulated patient participation and clinical-training students' reviews. J Jpn Acad Nurs Sci. 2006; 26(2): 67-75. https ://doi .org/10.5 630/jans.26.2_67

[14] Kitahara N, Bougaki T, Hirayama M, et al. Implementation of a teaching model based on self-directed learning preparation: Effects of the introduction of labeling work on students' 'level of satisfaction'. Teikyo University Faculty of Fukuoka Technology Bulletin. 2018; 13: 117-122.

[15] Tanaka H, Mitsui K, Manabe T. Relationship between students' learning and nursing competence in adult nursing practicums. The Bulletin of Ryotokuji University. 2018; 12: 105-115.

[16] Goh HS, Zhang H, Lee CN, et al. Value of Nursing objective structured clinical examinations: a scoping review. Nurse Educ. 2019; 44: E1-E6. PMid:30371544 https://doi .org/10.1097/NNE.0000 000000000620

[17] Belerson BV. Content analysis. In: G. Lindzey, ed. The handbook of social psychology. Cambridge, MA: Addison-Wesley; 1954; 488522.

[18] Scott WA. Reliability of content analysis: The case of nominal scale coding. Public Opin Q. 1955; 19(3): 321-325. https : //doi.org/ 10.1086/266577

[19] Chang CP, Lee TT, Mills ME, et al. E-portfolio functional requirements for the final semester baccalaureate practicum course: A qualitative research study. J Prof Nurs. 2019; 35: 405-411. PMid:31519345 https://doi.org/10.1016/j.profnurs. 201 9.04 .004

[20] Garrett BM, MacPhee M, Jackson C. Evaluation of an eportfolio for the assessment of clinical competence in a baccalaureate nursing program. Nurse Educ Today. 2013; 33(10): 1207-1213. PMid:22789875 https://doi.org/10.1016/j.nedt.2012.06.015

[21] Green J, Wyllie A, Jackson D. Electronic portfolios in nursing education: A review of the literature. Nurse Educ Pract. 2014; 14(1): 4-8 PMid:24090523 https://doi.org/10.1016/j.nepr.2013.08 .011 